\title{
A Comparative Study of Biomechanical Analysis for Anticipation of High Level and Beginner Female Goalkeepers in Handball.
}

\section{M. H. Alwan}

Ass. Prof. in the department of sports training and kinesiology, the faculty of sports education "for women", Alexandria University. Egypt.

\begin{abstract}
Biomechanics aims for analyzing sports performance for the ability of error correction to achieve peak performance and success levels. The aim of this study was to compare between the anticipation time and kinematic factors in the movement of high level and beginner female goalkeepers' center of mass when making a long-distance throw in handball. The sample group was composed of 14 female goalkeepers "7 high level and 7 beginners" and field players as shooters. A force platform was used to measure the force of the goalkeepers' reaction movements, while the throwers' movements were recorded with high-speed cameras. The high level female goalkeepers began to move $193 \pm 67 \mathrm{~ms}$ before the ball was released, with a $67 \%$ success rate of ball interception. The beginner female goalkeepers began their movement $209 \pm 127 \mathrm{~ms}$ with a $24 \%$ success rate. The time taken by high level female goalkeepers to begin a vertical movement of their CM, relative to the moment of the ball's release, was less than the time taken by beginner goalkeepers (77 $\pm 70 \mathrm{vs} .141 \pm 108 \mathrm{~ms}$ respectively). The analysis of the velocity and movement indicates that expert high level female goalkeepers waited longer time before moving than do inexperienced beginner female goalkeepers.
\end{abstract}

Key words: Biomechanics, Anticipation, Handball, Goalkeeper, Shots.

\section{Introduction}

$\mathbf{B}$ iomechanical studies of handball studies. The proper execution of handball skills involves the transfer of linear and angular momentum. Despite the transfer mechanisms through the body segments is a non explored concept in biomechanical research. Also the ability to intercept objects, which requires highly refined motor abilities and perception skills, is one of the most complex tasks of elite athletes in team sports. Many studies confirm that this skill is based on the ability to efficiently use cues from the opponent's movements in order to predict a precise technical action (Williams et al.,
1999; Abernethy and Zawi, 2007; Vignais et al., 2009). In this sense, one aspect distinguishing better performance of higher level players compared with less experienced or beginner ones is a superior ability to predict the opponent's actions and movements. Previous studies have shown that the ability to anticipate the path of an object in motion is related to the capacity of searching for and identifying directionality indicators (Savelsbergh et al., 2002; McRoberts et al., 2009; Cañal-Bruland et al., 2011) as well as adjusting the temporospatial motor response used for interception (Cañal-Bruland and Schmidt, 2009; Nabil and LaRue, 2011; Gutiérrez-Dávila et al., 
2011). Goulet et al. (1989) analyzed the visual reactions of expert and novice tennis players receiving a serve to identify directionality indicators. Expert tennis players focused their eye on the movement of the racket and the opponent's arm, while novice players focused only on the ball. Similarly, Cañal-Bruland et al. (2011) indicated that expert tennis players were better than inexperienced ones in predicting the direction of the serve, using cues from the arms and the racket.

Savelsbergh et al. (2002; 2005) using eye movement analysis techniques, examined different strategies to identify directional cues in expert and novice soccer goalkeepers. The expert players fixed their attention on the kicker's supporting leg and foot, and thereby identified the ball's direction more easily than its height. In starting a movement, the novice goalkeepers reacted $479 \mathrm{~ms}$ before the kicker's foot made contact with the ball, contrasting with only $230 \mathrm{~ms}$ for elite goalkeepers. In these studies, novice players varied in their reactions with hasty movements during the anticipation phase. However, expert and novice goalkeepers did not significantly differ in reaction time. Bideau et al. (2004) and Vignais et al. (2009) used virtual reality to study the response of elite handball goalkeepers, manipulating the amount of information that the test subject was able to gather during the ball's throw. The results indicated that a movement's precision diminishes when the amount of information during the anticipation phase is reduced, highlighting the relation between the information gathered during the anticipation phase and the technical execution of movements, especially the arms.

Cañal-Bruland and Schmidt (2009) and Cañal-Bruland et al. (2010), also using virtual-reality technology, showed that elite goalkeepers, compared to inexperienced ones or field players, have a superior ability to determine the ball's direction, responding appropriately, even against fakes.

In addition, the anticipatory movement by handball goalkeepers must take into account the fakes a thrower might employ. According to Fradet et al. (2004) and Van den Tillaar and Ettema (2009), the kinetic chain of handball throwers does not behave in a typical proximal-distal (P-D) sequence, since the direction of the throw can be changed at the last instant. Therefore, even if the goalkeeper can anticipate the direction of the throw, movement should ideally be delayed until it is difficult for the player to change the direction of the throw (Schorer et al., 2007; Gutiérrez-Dávila et al., 2011).

The purpose of this study was to compare and analyze the anticipation strategies of experienced team handball female goalkeepers vs. beginner female goal keepers. The methodology was based on data measured from the force of the goalkeeper's reaction synchronized with high-speed cameras that analyze the goalkeeper's anticipation in a situation where the relation between movement perception and action is preserved (Araujo and Davids, 2009). The objective of this study is to compare and analyze certain behavioral and biomechanical differences in the movement of the player's center of mass $(\mathrm{CM})$, related to ball release time and velocity, in elite vs. inexperienced goalkeepers. In this context, we hypothesize that expert goalkeepers will maintain a predetermined and efficient anticipation strategy, while inexperienced goalkeepers will show random anticipatory behavior. 


\section{Method}

\section{Participants}

Seven high level and seven inexperienced team handball female goalkeepers from $1^{\text {st }}$ degree Egyptian female handball league and university tournaments participants and four field players were appointed for this study. The experienced group was composed of team-handball female goalkeepers who had played in the first division of the Egyptian league (total experience $=14 \pm 8$ years, age $=$ $22 \pm 5$ years, body height $=1.76 \pm 0.03 \mathrm{~m}$, body mass $=69.79 \pm 9.93 \mathrm{~kg}$ ). The inexperienced group was composed of students from the Faculty of Sport education for women - Alexandria University who had participated as goalkeepers in team-handball university tournaments only (age $=19 \pm 5$ years, body height $1.70 \pm 0.04 \mathrm{~m}$, mass $=$ $62.42 \pm 7.29 \mathrm{~kg}$ ). The throwers were four team handball players, who were specialists in shooting and belonged to first division teams of the Egyptian League (age $=24 \pm 1$ years, body height $=1.86 \pm 0.05 \mathrm{~m}$, mass $=$ $76.32 \pm 5.18 \mathrm{~kg}$ ).

\section{Materials and apparatus}

The throws were made $10 \mathrm{~m}$ from the goal after a running start in a zone previously delimited by a reference system of $2.32 \mathrm{x}$ $1.58 \times 2 \mathrm{~m}$. A force platform $0.8 \times 0.8 \mathrm{~m}$ was situated in line with the center of the goal and one meter in front of the shooting zone. The throws were filmed using two high-speed digital video cameras, Redlake MotionScope PCI 1000S (San Diego, CA, USA), at a frequency of $500 \mathrm{~Hz}$, situated on the thrower's dominant side at $25 \mathrm{~m}$ from the geometric center of the shooting zone and 30 $\mathrm{m}$ apart. This same frequency was used to record the reaction force coming from the force platform. To synchronize the two cameras and the force platform, an electronic signal was used to activate the start (Figure $1)$.

The three-dimensional coordinates of five body points of the thrower (point of the left foot, center of the hip, shoulder, elbow and wrist) plus the point corresponding to the geometric center of the ball were determined for the throws chosen for analysis.

Figure 1

The experimental set-up used to collect data

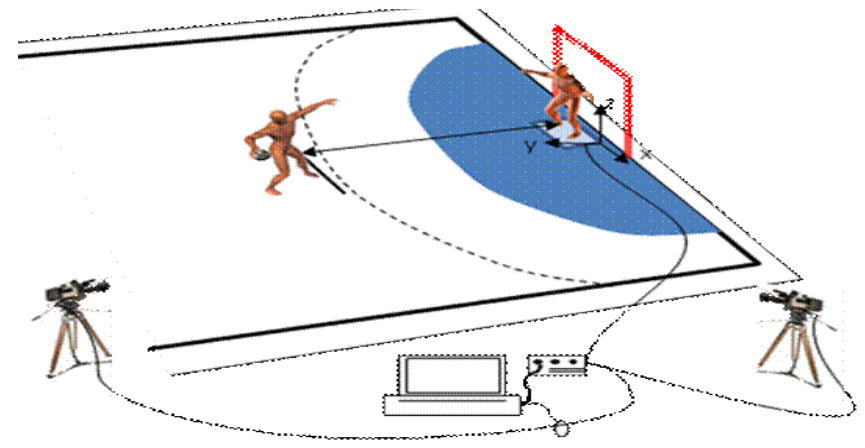

The calculations were made in three phases: were digitalized from the image received a) the position of the six points (landmarks) from the two high-speed video cameras, at a 
frequency of $125 \mathrm{~Hz}, \mathrm{~b}$ ) the method of direct linear transformation was used (Abdel-Aziz and Karara, 1971) to establish the threedimensional coordinates and c) Calculations were applied to the spatial coordinate established at this stage to smooth the spatial coordinates at the same frequency at which they were filmed $(500 \mathrm{~Hz})$.

\section{Procedures}

All female goalkeepers were instructed to situate themselves in their ready position on a force platform and not to move prior to the definitive action to save the ball. After the usual warm-up, each female goalkeeper attempted to intercept 10 shots. The save was considered valid only when the goalkeeper moved in the correct direction to intercept the ball, marking it as an error when the goalkeeper moved to the incorrect side or stood still. After recording 10 valid actions for each goalkeeper, we analyzed the five most accurate shots (accuracy being determined by the proximity of the ball to the upper or lower corners of the goal), to determine the differences between elite and inexperienced goalkeepers.

\section{Dependent variables}

The time of the throw (T(THROW)) was defined as the period between the end of the player's run up, considered as the instant when the whole foot made full contact with the ground and the instant of that the ball leaving the player's hand. The velocity of the ball at release from the player's hand (Vt(RELEASE)) was recorded. The beginning of the goalkeeper's horizontal and vertical movement related to ball release, $T$ START-X and TSTART-Z respectively, were recorded. TSTART-X was determined by using the data recorded from the transversal component of the reaction force, estimated at $0.001 \mathrm{~s}$ (half of the interval) before the instant in which net force reached a value greater than or equal to $1 \%$ of body weight. The error was determined by measuring the first 100 samples we recorded from the platform, where the goalkeeper was motionless before the player initiated the run (Gutiérrez-Dávila et al., 2006).

The instant of the start of the final movement of the vertical component of the CM (beginning of the acceleration impulse phase) related to ball release was considered to be the time when the vertical velocity of the CM became closest to zero (TSTART-Z). The following variables were recorded: the velocity of lateral movement of the goalkeeper's CM and the distance covered in $100 \mathrm{~ms}$ before the release of the ball (VX100 and eX-100, respectively); the velocity of lateral movement, and the distance covered at the instant of ball release (VXREL and eXREL, respectively); the velocity of vertical movement and the distance covered $100 \mathrm{~ms}$ before the ball release (VZ100 and eZ-100, respectively); the velocity of vertical displacement and the distance covered at the instant of ball release (VZREL and eZ-REL, respectively); and the maximum velocity of the vertical component during the anticipation period (VZ-MAX).

The instant transversal acceleration of the goalkeeper's CM $(a \mathrm{X})$ was calculated on the basis of the respective components of the goalkeeper's net force and mass. The transversal velocity $(v \mathrm{X})$ and displacement of the goalkeeper's CM (eX) were calculated from the respective functions of acceleration - time, using trapezoidal integration. After normalizing the vertical component by eliminating the body weight of each goalkeeper, the same procedure was used to determine vertical velocity $(v z)$. 


\section{Statistics}

The data were assessed for normality and homogeneity of variance, and are expressed as mean and standard deviation (SD). The mean and standard deviation (SD) of the variables were calculated for the expert and inexperienced goalkeepers. Each dependent measure was analyzed separately using a one- ay analysis of variance to quantify the differences between the average scores of the expert and inexperienced goalkeepers. The analysis was performed using SPSS software. The level for acceptance of significance $(\alpha)$ was set at 0.05 .

\section{Results}

Table 1 sets out the descriptive statistics and the significance level between the throwers for the average tangential velocity of the ball at the instant of release from the player's hand $(V t($ RELEASE $))$. The results reveal differences between the players $(F(3,126)=$ $4.44 p=0.01)$, player 3 achieving the highest average velocity $(25.43 \pm 1.44 \mathrm{~ms}-1)$ and player 2 the lowest $(23.88 \pm 2.12 \mathrm{~ms}-1)$. In general, the mean velocity reached in all the shots analyzed $(\mathrm{N}=129)$ was $24.57 \pm 1.76$ ms-1. Table 1 also shows the descriptive statistics and significance level of accuracy and the time of the shot $(\mathrm{t}(\mathrm{SHOT}))$ for each player. No statistically significant differences in accuracy were found among the players, while clear differences appeared in the time taken to make the shot $(F(3,126)=6.28 p=$ $0.0005)$, varying between $183 \pm 16 \mathrm{~ms}$ for player 2 and $237 \pm 23 \mathrm{~ms}$ for player 3 , the average of all shots being $206 \pm 30.3 \mathrm{~ms}$.

Table 2 shows the success and mistakes expressed in percentages of the throws. The elite female goalkeepers intercepted the ball in $66.3 \% \pm 7.5$ of the throws and committed errors only in $17.5 \% \pm 7.6$, while inexperienced goalkeepers achieved only $24.3 \% \pm 9.8$ success with errors in $42.1 \% \pm$ 11.2 of the throws, due to factors of nonmovement or movement in the wrong direction. In addition, the greater data spread for the inexperienced female goalkeepers indicates more erratic behavior. Table 2 also shows the average, typical deviation, and statistical significance of the behavioral and biomechanical variables analyzed with elite and inexperienced goalkeepers. The data shows that elite goalkeepers' lateral movement began $-193 \pm 67 \mathrm{~ms}$ before the ball left the hand of the thrower (TSTART$\mathrm{X}$ ), whereas inexperienced goalkeepers' lateral movement began $-209 \pm 127 \mathrm{~ms}$ before. The negative value of the times indicates that the beginning of the movement occurred before the ball's release.

Table 1

Descriptive Statistics and significance level of the velocity of the ball at the instant of release from the player's hand (Vt(RELEASE)), and the time of shot ( $t(T H R O W))$

\begin{tabular}{|c|c|c|c|c|c|}
\hline PLAYER & 1 & 2 & 3 & 4 & $F / p$ \\
\hline $\begin{array}{c}\text { Vt(RELEASE)) } \\
(\mathrm{ms}-1)\end{array}$ & $24.39 \pm 1.39$ & $23.88 \pm 2.12$ & $0.225 \pm 0.129$ & $183 \pm 16$ & $25.43 \pm 1.44$ \\
\hline Accuracy (m) & $0.242 \pm 0.117$ & $0.226 \pm 0.125$ & $237 \pm 23$ & $24.71 \pm 1.70$ & $0.253 \pm 0.132$ \\
\hline $\begin{array}{c}\text { T(THROW) } \\
(\mathrm{ms})\end{array}$ & $219 \pm 22$ & $184 \pm 17$ & $4.44^{* *}$ & 0.35 & 53.97 \\
\hline
\end{tabular}

$* * * \mathbf{p}<0.001 ; * * \mathbf{p}<0.01$ 
Table 2

Descriptive analysis of balls intercepted and mistakes made by the goalkeepers as well as significant differences of biomechanical variables between elite and inexperienced goalkeepers

\begin{tabular}{|c|c|c|c|}
\hline & $\begin{array}{l}\text { Elite goalkeepers } \\
\text { M SD }\end{array}$ & $\begin{array}{c}\text { Inexperienced } \\
\text { goalkeepers } \\
\text { M SD }\end{array}$ & $F / P$ \\
\hline Intercepted Balls (\%) & $66.3 \pm 7.5$ & $24.3 \pm 9.8$ & \\
\hline Mistakes (\%) & $17.5 \pm 7.6$ & $42.1 \pm 11.2$ & \\
\hline TSTART-X (ms) & $-193 \pm 67$ & $-209 \pm 127$ & 0.38 \\
\hline TSTART-Z (ms) & $77 \pm 70$ & $141 \pm 88$ & $7.24 * *$ \\
\hline VX-REL (ms-1) & $0.31 \pm 0.20$ & $0.32 \pm 0.26$ & 1.86 \\
\hline eX-REL (m) & $0.02 \pm 0.03$ & $0.04 \pm 0.05$ & 3.62 \\
\hline VX-100 (ms-1) & $0.09 \pm 0.12$ & $0.15 \pm 0.19$ & 0.04 \\
\hline eX-100 (m) & $0.01 \pm 0.01$ & $0.02 \pm 0.03$ & 1.18 \\
\hline VZ-100 (ms-1) & $-0.16 \pm 0.16$ & $-0.21 \pm 0.27$ & 0.68 \\
\hline eZ-100 (m) & $-0.01 \pm 0.03$ & $-0.03 \pm 0.06$ & 1.39 \\
\hline VZ-REL (ms-1) & $-0.16 \pm 0.21$ & $-0.32 \pm 0.33$ & $4.96 *$ \\
\hline eZ-REL (m) & $-0.03 \pm 0.04$ & $-0.05 \pm 0.08$ & 1.96 \\
\hline VZ-MAX (ms-1) & $-0.16 \pm 0.22$ & $-0.24 \pm 0.42$ & 0.88 \\
\hline
\end{tabular}

$* * \mathbf{p}<0.01 ; * \mathbf{p}<0.05$

The data referring to the start of the CM's vertical shift (TSTART-Z) indicate that expert female goalkeepers began this movement sooner than did inexperienced goalkeepers, the former's average time being $77 \pm 70 \mathrm{~ms}$ and the latter's $141 \pm 108 \mathrm{~ms}$, both in relation to the moment of the ball's release from the player's hand $(F(1,68)=7.24, p=$ $0.009)$. The positive values of the data indicate that in both cases the movements began after the ball was released from the player's hand. No statistically significant differences were detected in the transverse component of velocity and displacement by the goalkeeper's CM up to the moment of the ball's release (VX-REL and eX-REL, respectively). The average data for the same variables $100 \mathrm{~ms}$ after the release of the ball (VX-100 and eX-100, respectively) were similar. Despite no significant differences between the averages, the expert female goalkeepers achieved a slower transverse velocity and less displacement than did inexperienced female goalkeepers. The minimal significance between the averages was due to the variability of the results for the inexperienced female goalkeepers. Table 2 also shows the data relative to the velocity and space traveled in the vertical components of the CM's movement at the moment of the ball's release (VZ-REL and eZ-REL, respectively) as well as $100 \mathrm{~ms}$ before the release (VZ-100 and eZ-100, respectively). The measures of central tendency on the goalkeepers' vertical movements show statistically significant differences between expert and inexperienced subjects $(F(1,68)$ $=4.96, p=0.03)$. During the anticipation period, the experts demonstrated a clear tendency to lower their CM with a slower velocity than did their counterparts (VZREL) $(-0.16 \pm 0.21$ and $-0.32 \pm 0.33$, 
respectively) and therefore moved a shorter distance at the moment of the ball's release (ez-REL) $(-0.03 \pm 0.045 \mathrm{~m}$ and $-0.055 \pm$ $0.085 \mathrm{~m}$, respectively). This lesser vertical movement of the $\mathrm{CM}$ in expert goalkeepers is substantiated by the values recorded for maximum vertical velocity during the anticipation phase (VZ-MAX), which was less for expert players than for inexperienced ones $(-0.16 \pm 0.22 \mathrm{~m} / \mathrm{s}$ and $-0.24 \pm 0.42 \mathrm{~m} / \mathrm{s}$, respectively). Moreover, the spatial data as well as the data on velocity components show less dispersion in female expert goalkeepers.

\section{Discussion and conclusions}

As might be expected, the differences in the performance of both test groups confirm that the elite female goalkeepers were much more efficient at gathering and interpreting information during the anticipation period, which was subsequently used to determine a precise intercepting movement with a higher percentage of success. However, the inexperienced female goalkeepers intercepted fewer throws, found it difficult to anticipate and identify the path of the throws, and more frequently moved in incorrect directions. When they moved in correct directions, they lacked sufficient precision. These results coincide with those of Cañal-Bruland et al. (2010) and Vignais et al. (2009), who state that the ability to intercept a ball comes from precise technical execution, specifically of arm movements, and the ability to perceive cues up to the moment the ball leaves the player's hand.

The data gathered from the start of the female goalkeepers' movements, (TSTART$\mathrm{X})$ corroborate the studies of Savelsbergh et al. (2002, 2005) in which elite goalkeepers tended to begin movement before the thrower released the ball. The minor temporal difference in elite and inexperienced female goalkeepers supports the study by Vignais et al. (2009) reporting a similar response time between groups with varying experience levels. Nonetheless, the statistical values for the start of lateral movement, (TSTART-), are lower than those of Savelsbergh et al. (2002), who measured $230 \mathrm{~ms}$ for soccer goalkeeper using a joystick.

While the average time of the throws by the four participants (T(THROW)) was $206 \pm 30$ $\mathrm{ms}$, in all cases, elite as well as inexperienced goalkeeper movements commenced at the beginning of a throw (-193ms vs. $-209 \mathrm{~ms}$, respectively). Because of the high speeds of the ball, the goalkeepers needed to anticipate the throw in order to intercept it. The success of elite female goalkeepers' actions shows that they correctly identified the side to which the ball would be thrown based on cues from the throwers (technique and movements) before the ball was released. However, the inexperienced female goalkeepers made a higher number of mistakes, implying failure to identify signals in the throwers' technique, all of these findings agreeing with reports for other sports (Williams and Burwitz, 1993; Abernethy and Zawi, 2007). Compared to the same data on inexperienced goalkeepers, the smaller lateral displacement of elite goalkeepers, $100 \mathrm{~ms}$ before the release of the ball (ex-100), and the subsequent slower lateral velocity of the CM (VX-100) indicates that elite female goalkeepers may have detected certain cues indicating the direction of the throw, even though they began their movement without absolute certainty of the direction. These results coincide with the contributions of Savelsbergh et al. (2005), indicating that an elite soccer goalkeeper waits longer than an inexperienced one to decide on a reaction. 
This would help expert goalkeepers change their movement without signaling their reaction to the thrower. As the movement continues, the goalkeepers subsequently increase the horizontal distance traveled (eXREL) and the transverse velocity (Vx-REL) until the ball's release. At this point, it is more difficult for the player to alter the final direction of the throw without affecting its velocity (Fradet et al., 2004).

The data recorded on the vertical velocity of the female goalkeepers' CM show a clear tendency to lower the $\mathrm{CM}$ before the player releases the ball. The start of vertical movement (TSTART-Z) after the ball's release timed $77 \pm 70 \mathrm{~ms}$ for elite keepers and $141 \pm 108 \mathrm{~ms}$ for inexperienced ones, which could indicate a difficulty for the goalkeeper to determine the final height of the throw. In such a case, elite female goalkeepers, compared to inexperienced ones, might detect the height cues earlier. This contention is supported by the findings of Williams and Burwitz (1993) and Savelsbergh et al. (2005), who demonstrated that most errors made by soccer goalkeepers result from an incorrect perception of the factors determining shot height. The slower movement of elite female goalkeepers' $\mathrm{CM}$ at the moment of the ball's release (VZREL), the maximum vertical velocity during the anticipation period (VZ-MAX), and the lesser displacement of the CM (ez-REL), together, with the higher percentage of successful actions, indicates greater precision in the expert goalkeeper's movements, a key factor considered by Vignais et al. (2009).

Although elite female goalkeepers and inexperienced ones registered similar anticipation values for the direction of the throws (TSTART-X), most of the dispersion of the data indicates less precise and more poorly predetermined movement in the inexperienced goalkeepers. Also, their high number of errors reflects an incorrect perception of signals related to the throw direction and consequently erroneous interception movements. Meanwhile, elite goalkeepers registered a less dispersed dataset for the variables analyzed, indicating more controlled movement and more effective attention to the cues despite that throws were made in different directions. In addition to the analysis offered here, handball goalkeeper anticipation training (like the perception training proposed by Savelsbergh et al. (2010)) could focus on detecting key movements of the throwing player, thus making it more difficult for the player to alter the direction of the ball. These results suggest that handball goalkeepers should be trained to use an anticipation strategy with the following characteristics: a) the inhibition of the primary reaction responses based on unreliable indicators; b) to start moving slowly enough to avoid being perceived by the thrower and to allow a direction change before other indicators are perceived; c) to start a precise, rapid movement only at the end of the throwing action. On the contrary, when the players throw against inexperienced goalkeepers, they should expect a quick and premature movement towards the side of the throw, based on an inadequate identification of shot direction, in addition to erratic and imprecise motor responses.

Finally, it should be indicated that anticipation strategies described are determined by the distance, speed, and type of throw used in this study. By varying these factors, the player can alter anticipation strategies and, especially, movement patterns, as suggested by Nabil and LaRue (2011). 


\section{References}

1. Abdel-Aziz YI, Karara HM. Direct linear transformation from comparator coordinates into object space coordinates in close-range photogrammetry. ASP Symposium on Close-Range photogrammetry Illinois: Falls Church, 1971; 1-18

2. Abernethy B, Zawi K. Pickup of Essential Kinematics Underpins. Expert Perception of Movement Patterns. J Motor Behav, 2007; 39(5): 353-367

3. Araujo D, Davids K. Ecological approaches to cognition and action in sport and exercise: Ask not only what you do, but where you do it. Int J Sport Psychol, 2009; 40: 5-37

4. Bideau B, Multon F, Kulpa R, Fradet L, Arnaldi B, Delamarche P. Using virtual reality to analyze links between handball thrower kinematics and goalkeeper's reactions. Neurosci Lett, 2004; 372: 119-122

5. Cañal-Bruland R, Schmidt M. Response bias in judging deceptive movements. Acta Psychol, 2009; 130: 235-240

6. Cañal-Bruland $R$, van Ginneken $W F$, van der Meer BR, Williams AM. The effect of local kinematics changes on anticipation judgments. Hum Movement Sci, 2011; 30(3): 495-503

7. Cañal-Bruland R, Van der Kamp J, Van Kesteren J. An examination of motor and perceptual contributions to the recognition of deception from others' actions. Hum Movement Sci, 2010; 29: 94-102

8. Fradet L, Botcazou M, Durochel C, Cretual A, Multon F, Prioux J, Delamarche P. Do handball throws always exhibit a proximalto-distal segmental sequence? J Sports Sci, 2004; 22: 439-447

9. Goulet C, Bard C, Fleury M. Expertise differences in preparing to return a tennis serve: A visual information processing approach. $J$ Sport Exercise Psy, 1989; 11: 382-398

10. Gutiérrez-Dávila M, Dapena J, Campos J. The effect of muscular pre-tensing on the sprint start. J Appl Biomech, 2006; 22, 3: 194-201

11. Gutiérrez-Dávila M, Rojas FJ, Ortega M, Campos J, Párraga J. Anticipatory
Strategies of Team-Handball Goalkeepers. $J$ Sports Sci, 2011; 29(12): 1321-1328

12. Huys R, Cañal-Bruland R, Hagemann N, Beek P, Smeeton N, Williams M. Global Information Pickup Underpins Anticipation of Tennis Shot Direction. J Motor Behav, 2009; 41, 2: 158-170

13. McRobert AP, Williams AM, Ward P, Eccles DW. Tracing the process of expertise in a simulated anticipation task. Ergonomics, 2009; 52: 474-483

14. Nabil I, LaRue J. Modulation of anticipatory postural adjustments in the anticipation-coincidence task. $J$ Motor Behav, 2011; 43(4): 333-344

15. Savelsbergh GJP, Williams AM, Van der Kamp J, Ward P. Visual search, anticipation and expertise in soccer goalkeepers. J Sports Sci, 2002; 20: 279-287

16. Savelsbergh GJP, Van der Kamp AM, Williams AM, Ward P. Anticipation and visual search behaviour in expert soccer goalkeepers. Ergonomics, 2005; 48: 15861697

17. Savelsbergh GJP, Van Gastel PJ, Van Kampen PM. Anticipation of penalty kicking direction can be improved by directing attention through perceptual learning. Int J Sport Psychol, 2010; 41: 24-41

18. Schorer J, Fath F, Baker J, Jaitner $T$. Identification of inter-individual and intraindividual movement patterns in handball players of varying expertise levels. $J$ Motor Behav, 2007; 39, 5: 409-421

19. Van den Tillaar R, Ettema G. Is there a proximal-to-distal sequence in overarm throwing in team handball? $J$ Sports Sci, 2009; 27(9): 949-955

20. Vignais N, Bideau B, Craig $C$, Brault $S$, Multon F, Delamarche P, Kulpa R. Does the level of graphical detail of a virtual handball thrower influence a goal-keeper's motor response? J Sports Sci Med, 2009; 8: 501-508

21. Williams AM, Burwitz L. Advance cue utilization in soccer, in Science and Football II (eds. T.Reilly, J.Clarys and A. Stibbe) Ed. FN Spon, 239-243; 1993

22. Williams AM, Davids K, Williams JG. Visual Perception and Action in Sport. London and New York: E and FN Spon; 1999 
